\title{
Development and Application of an Intelligent Evaluation and Control Platform for Tunnel Smooth Blasting
}

\author{
Baoping Zou $\mathbb{D},,^{1,2}$ Zhanyou Luo $\mathbb{D}^{1}{ }^{1}$ Jianxiu Wang $\mathbb{D},^{2}$ and Lisheng Hu $\mathbb{D}^{3}$ \\ ${ }^{1}$ School of Civil Engineering and Architecture, Zhejiang University of Science and Technology, Hangzhou 310023, China \\ ${ }^{2}$ Department of Geotechnical Engineering, Tongji University, Shanghai 200092, China \\ ${ }^{3}$ China Railway No.2 Engineering Group Co., Ltd., Chengdu 610031, China
}

Correspondence should be addressed to Baoping Zou; zoubp@zust.edu.cn

Received 9 December 2020; Revised 20 December 2020; Accepted 8 January 2021; Published 9 February 2021

Academic Editor: Feng Xiong

Copyright ( 2021 Baoping Zou et al. This is an open access article distributed under the Creative Commons Attribution License, which permits unrestricted use, distribution, and reproduction in any medium, provided the original work is properly cited.

Many tunnels around the world are still being constructed by drilling and blasting because these methods have an unmatched degree of flexibility relative to machine excavations using tunnel boring machines. At present, a large gap exists between evaluation theory and the control application of tunnel smooth blasting (TSB) quality. In this study, a handheld mobile platform that is based on the Android system and is written in the Java language is proposed to evaluate and control the performance of TSB. The function of this handheld mobile platform mainly includes data input, data modification, data deletion, weight setting for smooth blasting evaluation, smooth blasting quality assessment, and smooth blasting quality control. Using the proposed mobile platform, end users can evaluate and control TSB quality after each blast. The proposed handheld mobile platform is also applied to the real case history of line 6 in Guangzhou, China.

\section{Introduction}

A large amount of tunnels in the world are still constructed by drilling and blasting as the method has an unmatched degree of flexibility compared with machine excavations using tunnel boring machine (TBM). The quality of tunnel smooth blasting (TSB) heavily affects the safety and speed of tunnel construction [1]. Some problems, such as the overbreak and underbreak of a tunnel, frequently occur during smooth blasting. A stable and efficient monitoring platform has to be developed to evaluate and control the TSB construction. The platform has to contain a strong quality evaluation algorithm based on the geological and explosion conditions in engineering practices [2-6]. A user-friendly interface and simple operation system are also required in the monitoring platform.

Some studies have been conducted to develop the software to monitor and evaluate the quality of the TSB. One of such example is a system dynamic model (SDM) proposed by Abbaspour et al. [7] to optimize the explosion parameters based on an interactive system. Cardu and Seccatore [8] proposed a method for quantifying and classifying the difficulty of tunneling. Hasanipanah et al. [9] investigated the rock engineering system (RES) technique to evaluate the risk associated with rock fragmentation. Yang et al. [10] assembled a set of expert systems that incorporates the typical explosion case, explosion theory and rules, expert experience, and an industry-standard knowledge base of tunnel blasting design. The CAD-based mapping function was established with two development technologies. Katsuyama [11] employed numerical simulation technology to study the explosion process. Verma and Singh [12] used the optimization control technology for the GA (genetic algorithm) to predict the peak particle velocity that optimizes the explosion parameters. La Rosa [13] developed an expert system for explosion design that can be utilized to complete the explosion design. Lee et al. [14] developed an automatic design procedure for tunnel explosion that can predict the velocity of explosion vibration particles. Kecojevic and Wilkinson [15] developed a system of CAD and 
high-precision drilling and blasting design that can be used in drilling and blasting operations. However, all the proposed platforms are computer based and are not convenient to be used in field practice to access the database and design TSB parameters. Furthermore, the qualities of TSB in these platforms cannot be automatically predicted, evaluated, and controlled.

The existing methods for the quality assessment of TSB depend on decision makers' personal project experience and subjective understanding [16-25]. A qualitative evaluation of blasting quality is mainly conducted on the basis of artificial observations. Thus, the existing quality decision control of tunnel blasting, including visual observation and experience judgment, is mainly performed by humans. Therefore, a considerable disconnect exists between the existing theory of TSB quality assessment and control applications, and providing decision support for the quality evaluation and control of TSB is difficult. For example, in the evaluation of TSB quality, if a part of a tunnel has a large overbreak but the overbreak area is extremely small (see Figure 1) and if TSB quality is evaluated according to indexes such as overbreak and underbreak, one cannot easily judge the grade of TSB quality according to the existing tunnel specifications in China. In another example, the surrounding rock in TSB quality control for heterogeneous anisotropic discontinuity contains a large number of adverse geological structures, such as joints, fissures, weak interlayers, and faults. According to the existing tunnel specifications in China, a single control of peripheral hole spacing, minimum resistance line, and linear charge density cause considerable overbreak (see Figure 2). In tunnel excavations, overbreak is the main cause of not only safety hazards but also additional costs. Therefore, the key to an effective quantitative assessment and intelligent decision control of TSB quality is to build a collaborative decision-making system for real-time assessment and intelligent control that can quantitatively evaluate the quality of each blast in real time. Moreover, such system should provide control suggestions and the control values of blasting parameters for the next blasting cycle under complex tunnel sites.

In this paper, a handheld mobile platform based on the Android system written in the Java language is proposed to evaluate and control the TSB construction. The design of the software framework, system functions, system modules, and user interfaces are discussed. Using the proposed mobile platform, the end users can monitor and evaluate the TSB quality after each blasting. The platform also provides functions to the end users for the purpose of secondary development. The proposed mobile platform was also applied to a real case history in metro line six in Guangzhou, China.

\section{Software Framework}

The system should at least be composed of the following six major functions: data input, data modification, data deletion, weight setting, quality evaluation, and quality control. The function of the data input is to add the basic information for TSB, such as the section number, control index, and evaluation index. The functions of data modification and

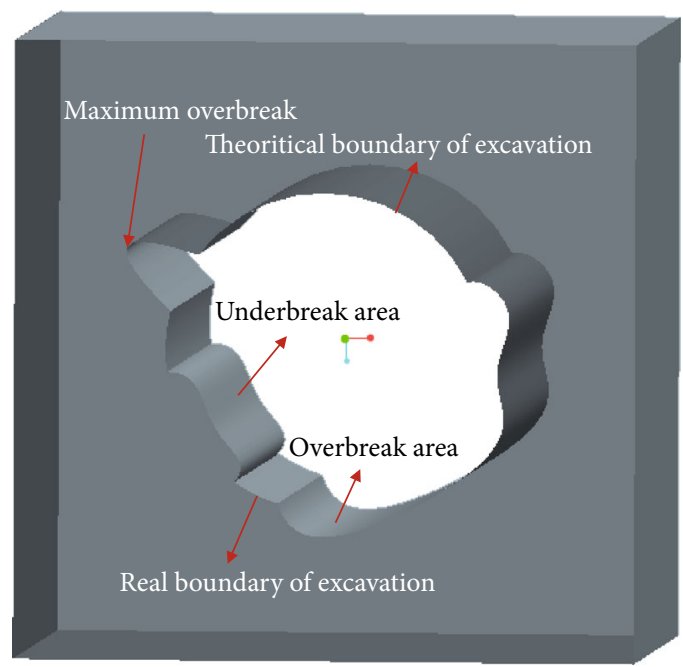

FIGURE 1: Overbreak and underbreak in the tunnel smooth blasting.

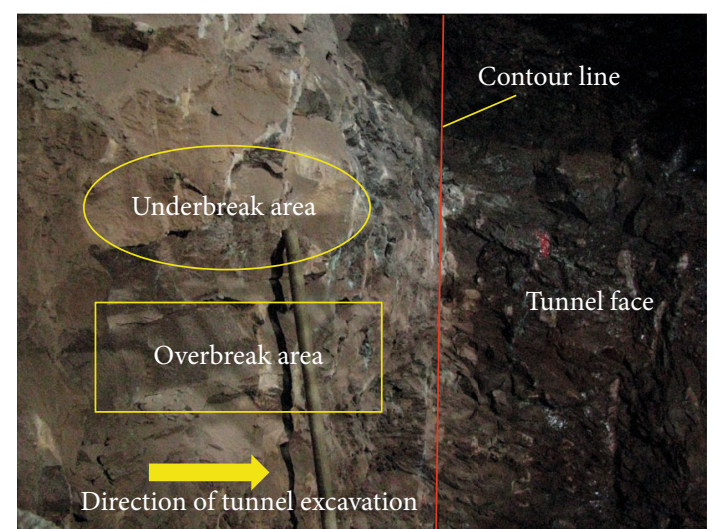

FIGURE 2: Adverse geological structures induced overbreak and underbreak.

deletion are used to modify and delete the data inputs, respectively. The function of weight setting is to set the index weight coefficient of the quality evaluation of the TSB. The weight coefficient of TSB quality evaluation can be calculated according to many cases of TSB based on multiple sets of weight coefficients for TSB quality. The function of the quality evaluation is to evaluate the quality of TSB parameters via a comprehensive index evaluation method for the grading evaluation of TSB quality, and thus, it gives end users a basic guide for current TSB construction. The evaluation results are displayed in the form of a score for the comprehensive quality evaluation index and for smooth blasting quality level. The function of quality control is to analyze each smooth blasting evaluation index in the evaluation index system through the BP neural network, the Adaptive Neuro-Fuzzy Inference System (ANFIS) neural network, and the Elman neural network. The function can be used to guide the following TSB according to the hole dimensions after current TSB. The system functions in the handheld mobile platform are summarized in Figure 3. 


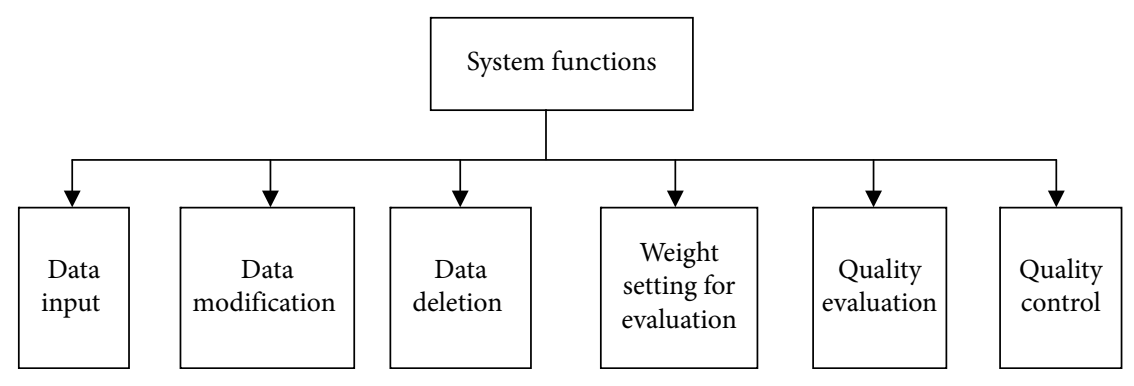

Figure 3: System functions.

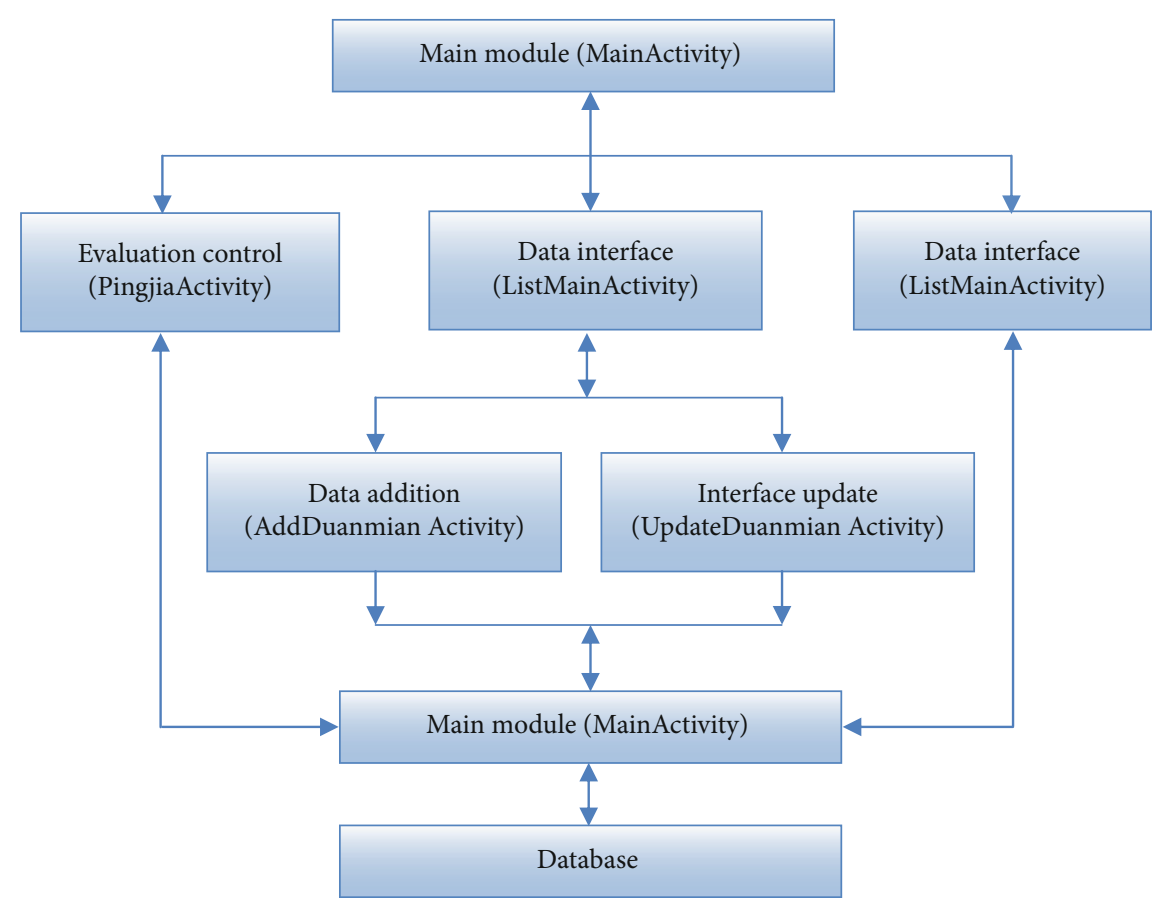

Figure 4: Modules of system function.

To achieve the six system functions, eight main modules have to be developed, such as data interface, data addition, interface update, weight setting, evaluation control, data storage service, and database. The relationships between the modules of the system functions in the handheld mobile platform are summarized in Figure 4.

The platform of TSB is designed with nine user interface functions to facilitate communication between users and systems. These interfaces are the main interface (Figure 5(a)), cross-sectional data list (Figure 5(b)), section addition (Figure 5(c)), section update, evaluation (Figure 5(d)), control (Figure 5(e)), advanced settings (Figure 5(f)), weight settings (Figures $5(\mathrm{~g})$ and $5(\mathrm{~h})$ ), and help. The main interface consists of four components, such as the evaluation, data, set, and help buttons, as shown in Figure 5(a). The users can press different operation buttons to enter the appropriate interface according to the varying needs of the evaluation process for TSB. The cross-sectional data lists are used to gather the evaluated data of the section of TSB. When a user clicks on the "add a section" button, the system enters the interface of adding a section (Figure 5(c)) and the section number will be added to the section number list (Figure 5(b)). The sectional information involves rock mass classification, detonation velocity, peripheral hole spacing, minimum resistance line, relative distance, linear charge density, the initiation sequence, excavation method, and online measurement. The user could also edit or even delete the added section number information. The evaluation index (Figure 5(d)) depicts the assessment process of the quality of the TSB score and that of smooth blasting evaluation grade. The software combines the rock data evaluation and the smooth blasting parameters to present the opinion regarding tunnel blasting control.

The control interface (Figure 5(e)) manages TSB quality. The name of the cross section is presented in the upper left of the control interface. The center of the screen depicts the BP, ANFIS, and Elman neural networks of the three types of methods. The evaluation section control index is incorporated, 


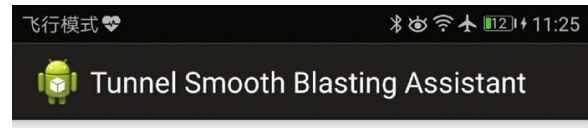

\begin{tabular}{|c|}
\hline \\
\hline Evaluate \\
\hline Data \\
\hline Set \\
\hline Help \\
\hline
\end{tabular}

\section{$\triangleleft$}

$\bigcirc \quad \square$

(a)

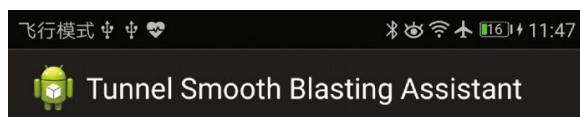

Add smooth blasting data

Section No. :

Control index

Rock mass classification :

Detonation velocity $(\mathrm{m} / \mathrm{s})$ :

Peripheral hole spacing $(\mathrm{mm})$ :

Minimum resistance line $(\mathrm{m})$ :

Relative distance :

Linear charge density $(\mathrm{kg} / \mathrm{m})$ :

Initiation order :

Excavation method:

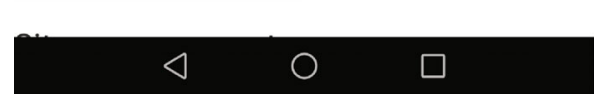

(c)

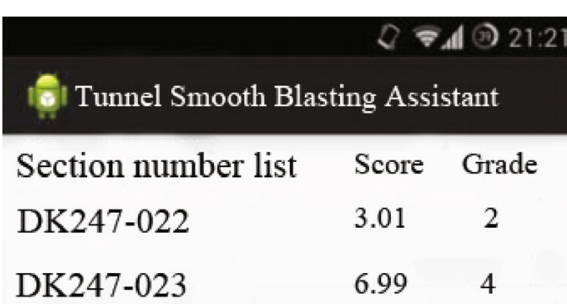

DK247-023

$6.99 \quad 4$

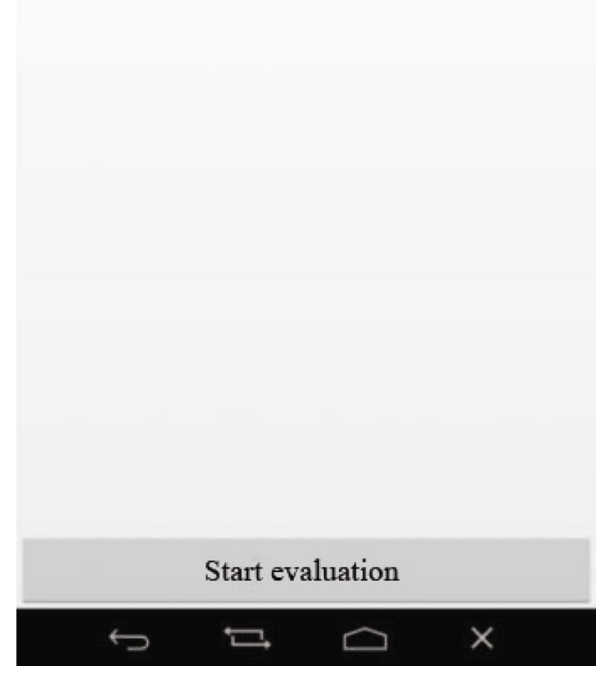

(b)

\section{飞行模式中

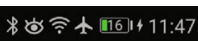 \\ बृ̣̂ㄴ Tunnel Smooth Blasting Assistant}

Evaluation index

Maximum overbreak (m) :

Average linear overbreak (m):

Maximum underbreak (m) :

Maximum size of the hole steps $(\mathrm{cm})$ :

Overbreak area (sq.m.) :

Sectional area measurement (sq.m.):

Overbreak rate (\%) :

Overbreak volume (cu.m.) :

Hole utilization ratio (\%) :

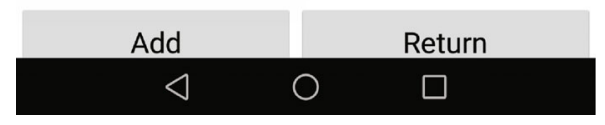

(d)

Figure 5: Continued. 


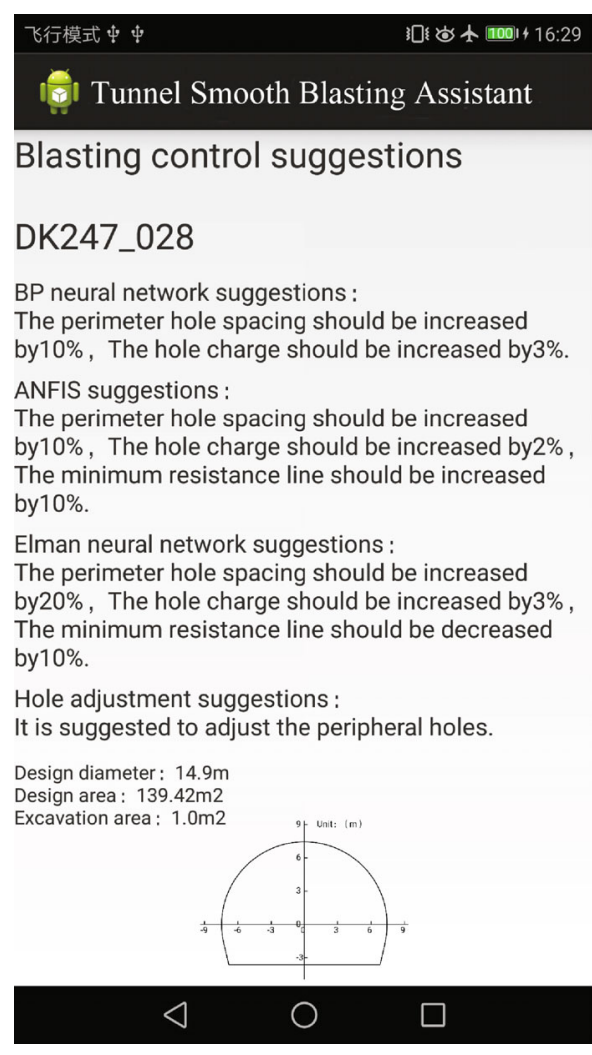

(e)

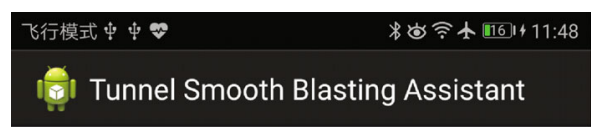

\section{Weight setting}

Maximum overbreak (m) :

Average linear overbreak (m):

Maximum underbreak (m) :

Maximum size of the hole steps $(\mathrm{cm})$ :

Overbreak area (sq.m.) :

Sectional area measurement (sq.m.) :

Overbreak rate (\%) :

Overbreak volume (cu.m.) :

Hole utilization ratio (\%) :

$\mathrm{O}$

(g)

飞行模式 $\psi$ $\Psi$ advanced setting
WEIGHT SETTING
Weight setting
Set the weight of the evaluation method
CONTROL THE OUTPUT SETTINGS

Output of the BP neural netwo... Current state: selected

Output of the ANFIS neural ne...

Current state: selected

Output of the Elman neural ne... Current state: selected

\section{ADVANCED SETTING}

New file

Open file

Save file

$\triangleleft \quad \bigcirc \quad \square$

(f)

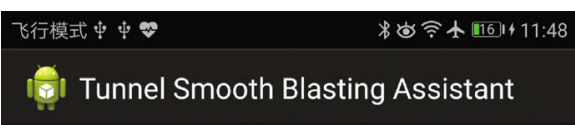

Overbreak area (sq.m.) :

Sectional area measurement (sq.m.) :

Overbreak rate (\%) :

Overbreak volume (cu.m.) :

Hole utilization ratio (\%) :

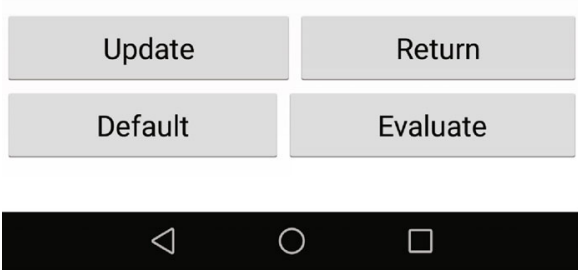

(h)

FIGURE 5: User interface in the handheld mobile platform: (a) main interface, (b) cross-sectional data list interface, (c) interface of section addition and update, (d) evaluation interface, (e) control interface, (f) advanced settings interface, (g) first page of weight setting interface, and (h) first page of weight setting interface. 
TABle 1: Set of data types of the database.

\begin{tabular}{|c|c|c|c|}
\hline Index type & $\begin{array}{c}\text { Data name } \\
\text { Number } \\
\text { Section number }\end{array}$ & $\begin{array}{c}\text { Field name } \\
\text { id } \\
\text { No_blasthole }\end{array}$ & $\begin{array}{c}\text { Type } \\
\text { INTEGER } \\
\text { CHAR }(20)\end{array}$ \\
\hline \multirow{9}{*}{ Control index } & Rock mass classification & rock_classification & DOUBLE \\
\hline & Detonation velocity $(\mathrm{m} / \mathrm{s})$ & blast_speed & DOUBLE \\
\hline & Peripheral hole spacing $(\mathrm{mm})$ & hole_space & DOUBLE \\
\hline & Minimum resistance line $(\mathrm{m})$ & least_resistance & DOUBLE \\
\hline & Relative distance & relative_distance & DOUBLE \\
\hline & Linear charge density $(\mathrm{kg} / \mathrm{m})$ & charge_density & DOUBLE \\
\hline & Initiation order & blast_order & DOUBLE \\
\hline & Excavation method & excavate_method & DOUBLE \\
\hline & Site measurement & measurement & DOUBLE \\
\hline \multirow{3}{*}{ Point index } & Maximum overbreak (m) & max_overbreak & DOUBLE \\
\hline & Maximum underbreak (m) & max_underbreak & DOUBLE \\
\hline & Average linear overbreak (m) & ave_overbreak & DOUBLE \\
\hline Line index & Maximum size of the hole steps $(\mathrm{cm})$ & gun_stepsize & DOUBLE \\
\hline \multirow{3}{*}{ Area index } & Area of the section for measurement $\left(\mathrm{m}^{2}\right)$ & area & DOUBLE \\
\hline & Overbreak area $\left(\mathrm{m}^{2}\right)$ & overbreak_area & DOUBLE \\
\hline & Overbreak rate (\%) & overbreak_rate & DOUBLE \\
\hline \multirow{2}{*}{ Volume index } & Overbreak volume $\left(\mathrm{m}^{3}\right)$ & overbreak_volume & DOUBLE \\
\hline & Hole utilization ratio (\%) & blasthole_utilization & DOUBLE \\
\hline \multirow{4}{*}{ Evaluation level } & Evaluation score 1 & effect_1 & DOUBLE \\
\hline & Evaluation score 2 & effect_2 & DOUBLE \\
\hline & Evaluation grade 1 & class_1 & INTEGER \\
\hline & Evaluation grade 2 & class_2 & INTEGER \\
\hline \multirow{4}{*}{ Control suggestion } & $\mathrm{BP}$ recommendation & bp_suggestion & $\operatorname{CHAR}(100)$ \\
\hline & ANFIS recommendation & anfis_suggestion & $\operatorname{CHAR}(100)$ \\
\hline & Elman recommendation & elman_suggestion & $\operatorname{CHAR}(100)$ \\
\hline & Control suggestion & control_suggestion & $\operatorname{CHAR}(100)$ \\
\hline
\end{tabular}

and the smooth blasting parameters are calculated after conducting the comprehensive control methods. The adjustment opinion of the tunnel is presented at the bottom of the screen according to the measurement data of the tunnel section. The contrast between the smooth blasting profile of the tunnel and the design outline is also displayed in this area. The measurement information of the cross section is presented at the upper left of the comparison chart, including the diameter of the design section, the area of the design section, and the area of the section for measurement. The advanced setting interface mainly includes weighting, control output settings, and file path as shown in Figure 5(f). The BP neural network, ANFIS, and Elman neural networks can be selected by the users to set the control output setting which can be used to recommend the TSB quality.

The weight setting interface is aimed at evaluating the index for weight assignment based on an established index system for the evaluation of TSB quality, as shown in Figures 5(g) and 5(h). The update button is used to facilitate index weight calculation, which is conducted to obtain the index weight for reentering the intelligent evaluation and control platform for TSB. The update button is used to save the weight coefficient. The update is completed simply by entering the operating interface. The page reverts to the main interface when users click the return button. When users press the default button, the text boxes for the evaluation index parameters on the operation screen are automatically filled with the default weight coefficient of the system, which is applied to calculate the weight of the TSB quality grade via the comprehensive index evaluation method. The default weight is then saved into the software. The user can use the evaluation button to get the evaluation of TSB quality after the weight coefficient is completely set up. The help interface primarily shows the basic principle of software implementation and the software instructions.

\section{Main Module of the Android Platform}

The code in the Java language generates the classes of DataModel, MyDbhelper, and Service to produce smooth blasting 
private void pingjiajisuan ()\{

String PREF_NAME = "quzhong_shezhi";

String PREF_1 = "avg_linear_overbreak";

String PREF_2 = "max_overbreak";

…...

//int lastid = service.getLastId();

int lastid $=100$;

double[] $\mathrm{a}=$ new double [5];

double[] quanzhong $=$ new double [5];

SharedPreferences $\mathrm{sp}=$ getSharedPreferences $($ PREF_NAME,

Context.MODE_WORLD_WRITEABLE);

quanzhong $[0]=$ Double.valueOf(sp.getString(PREF_1,"'));

boolean result $=$ service. updatePingjia $($ model $)$;

effect_1 $1=0$;

effect_2 $=0$;

class_1 $=0$;

class_2 $=0$;

\}

renderDuanmianList();

\} \}

Pseudocode 1: Evaluation function code.

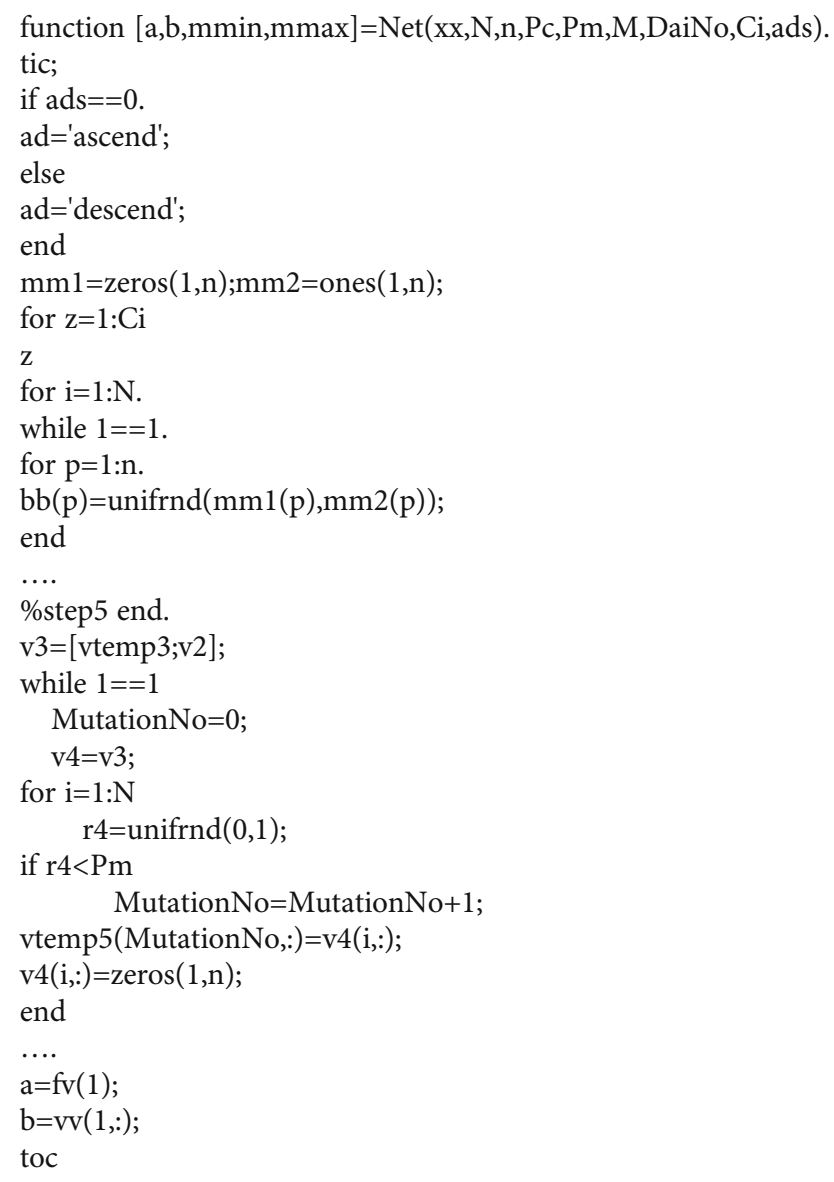




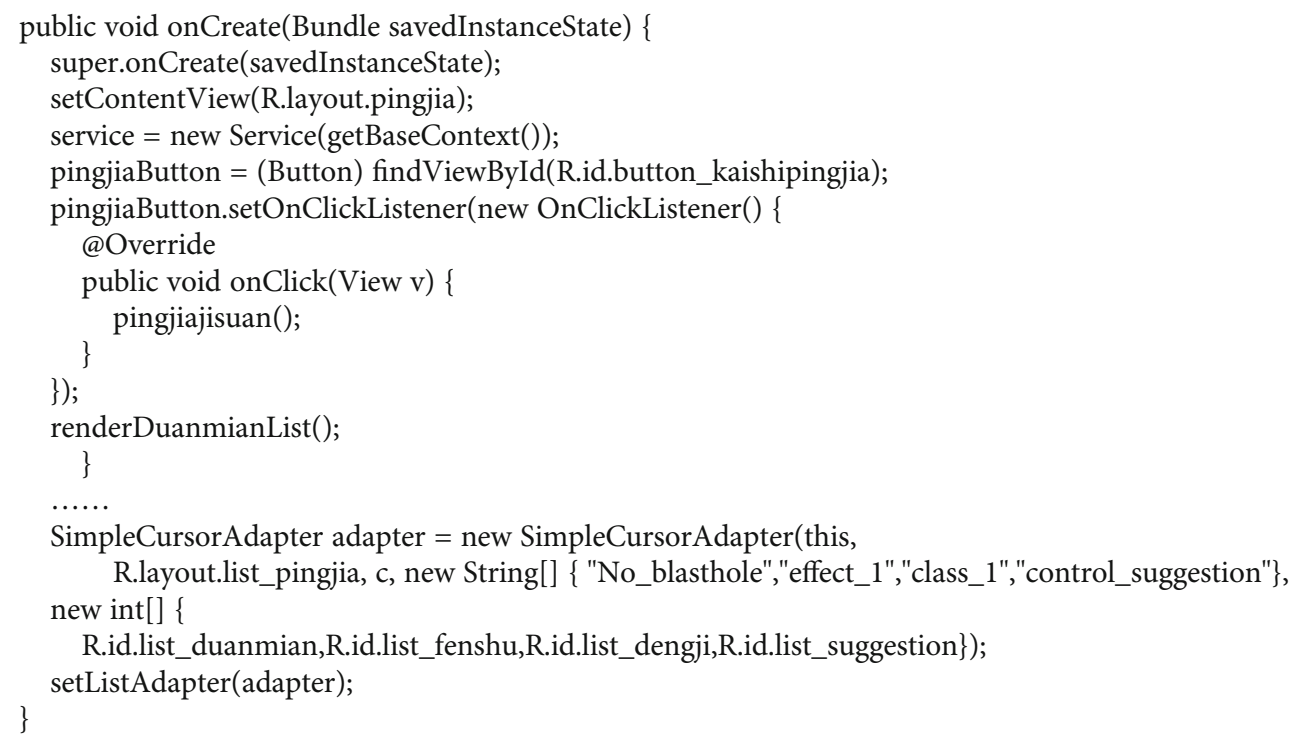

Pseudocode 3: Evaluate and control interface code.

TABLE 2: Smooth blasting parameters.

\begin{tabular}{lcccc}
\hline $\begin{array}{l}\text { Rock mass } \\
\text { classification }\end{array}$ & $\begin{array}{c}\text { Peripheral hole spacing } \\
(\mathrm{cm})\end{array}$ & $\begin{array}{c}\text { The resistance line of the peripheral } \\
\text { hole }(\mathrm{cm})\end{array}$ & $\begin{array}{c}\text { Intensive coefficient } \\
\mathrm{E} / \mathrm{W}\end{array}$ & $\begin{array}{c}\text { Charging concentration } \\
(\mathrm{kg} / \mathrm{m})\end{array}$ \\
\hline II & 50 & 60 & 0.83 & 0.30 \\
\hline
\end{tabular}

TABLE 3: Hole arrangement parameters.

\begin{tabular}{|c|c|c|c|c|c|c|c|}
\hline Location & $\begin{array}{c}\text { Serial } \\
\text { number }\end{array}$ & Name & $\begin{array}{l}\text { Hole depth } \\
\quad(\mathrm{m})\end{array}$ & Blastholes & $\begin{array}{c}\text { Explosive charge in per hole } \\
(\mathrm{kg})\end{array}$ & $\begin{array}{c}\text { Initiation } \\
\text { order }\end{array}$ & $\begin{array}{l}\text { Millisecond } \\
\text { stage }\end{array}$ \\
\hline \multirow{6}{*}{$\begin{array}{l}\text { Whole } \\
\text { section }\end{array}$} & 1 & Cutting hole & 2.8 & 10 & 2.4 & 1 & 1 \\
\hline & 2 & $\begin{array}{l}\text { Auxiliary } \\
\text { hole }\end{array}$ & 2.5 & 8 & 1.8 & 2 & 3 \\
\hline & 3 & $\begin{array}{l}\text { Auxiliary } \\
\text { hole }\end{array}$ & 2.5 & 16 & 1.5 & 3 & 5 \\
\hline & 4 & $\begin{array}{l}\text { Auxiliary } \\
\text { hole }\end{array}$ & 2.5 & 25 & 1.5 & 4 & 7 \\
\hline & 5 & Bottom hole & 2.5 & 9 & 1.2 & 5 & 9 \\
\hline & 6 & $\begin{array}{c}\text { Side } \\
\text { borehole }\end{array}$ & 2.5 & 29 & 0.75 & 6 & 11 \\
\hline
\end{tabular}

data and facilitate operations such as access, modification, and deletion. The DataModel class constructs the model parameters, MyDbhelper establishes a database, and the Service class is responsible for all data additions and deletions to change the search operation. The MyDbhelper database is a named list which is a key to the database. The data types are summarized in Table 1. This service is the core of the entire database operation. Service() is a constructor, saveDuanmian() denotes the sample data in the database, getLastId int () represents the amount of data acquired, getDuanmian() is aimed at obtaining the entire database of data, Id number represents the process by which getDuanmianById () reverts to this ID data model, updateDuanmian () is intended to update the data, deleteDuanmian () is aimed at deleting a section of data, and updatePingjia () updates a section of the evaluation results. The evaluation functions and the weight coefficients of the method for the comprehensive index evaluation of TSB quality are also coded using the Java language. The smooth blasting data are primarily evaluated and calculated using the FOR loop. The same process is used to realize the control suggestion. The evaluation index value of the data is obtained for a given datum. The weight of the 
index corresponding to the XML file is determined with the class_1 file. The betal function is utilized to calculate the value of class_2, and the code is shown in Pseudocode 1.

The control functions of the majority of the codes are written in MATLAB. Moreover, the $\mathrm{m}$-file is written into the Java package and then imported into Eclipse. The control function code is shown in Pseudocode 2. The evaluation interface of ListView has four TextView controls when the layout file is used. These controls correspond to the section number, score, quality evaluation grade, and the second line of control recommendations. The evaluation and the control functions are run after the activation of the start evaluation button at the bottom of the screen, and the results are displayed on the evaluation interface. The code is shown in Pseudocode 3.

\section{Engineering Application}

4.1. Engineering Survey. The proposed mobile platform was also applied to a real case history in metro line six in Guangzhou, China. The length of the test line is SSK0 +724.5 , whereas the length of the tunnel is $748.4 \mathrm{~m}$. The tunnel is a horseshoe-shaped composite lining structure, and the lining section comprises five types, i.e., B, C, D, E, and A. The size of the cross section ranges from $6200 \mathrm{~mm} \times 6637 \mathrm{~mm}$ to $6500 \mathrm{~mm} \times 7437 \mathrm{~mm}$. The overbreak and backfill processes use C25 to spray early strength concrete.

The rock strata in the tunnel area mainly include the following: (1) hard plastic and the residual soil of hard plastic granite named as 5H-2 composed of sandy clay, gravel, weathered residual quartz particles, and a hard plastic to hard clay with a thickness of $0.30-37.40 \mathrm{~m}$ and average thickness of $8.16 \mathrm{~m}$; (2) fully weathered granite zone (named as $6 \mathrm{H}$ ) containing granite in brown, gray, black, and brown color with thickness of $0.20-35.20 \mathrm{~m}$ and the average thickness of $8.01 \mathrm{~m}$; (3) strong granite weathering zone (named as $7 \mathrm{H}$ ) containing granite in brown, gray, black, and brown color with well-developed weathering fissures and thickness of $0.20-19.50 \mathrm{~m}$ and the average thickness of $4.51 \mathrm{~m}$; (4) granite weathering zone (named as $8 \mathrm{H}$ ) containing granite with medium-fine grained and massive structures in light brown, gray, and brown color with layer thickness of $0.20-15.50 \mathrm{~m}$ and the average thickness of $2.83 \mathrm{~m}$; and (5) granite breeze belt (named as 9H) containing granite with medium-fine grained and massive structures in light gray and gray and thickness of 0.50-43.90 m and average thickness of $9.07 \mathrm{~m}$. The main part of the tunnel passes through the $9 \mathrm{H}$ granite breeze belt layer. The compressive strength of the dry granite ranges from $65 \mathrm{MPa}$ to $152 \mathrm{MPa}$ with their average value of 100.3 MPa. The natural compressive strength ranges from 53.3 to $126.0 \mathrm{MPa}$.

4.2. Analysis of Blasting Quality before Implementation. The SSK0 + 715 excavation cycle is selected to monitor the experimental ring. To provide a reference basis for the implementation of TSB control in the experimental cycle tunnel, the smooth blasting of SSK0 +712 in the first excavation of the test ring excavation cycle was analyzed prior to the incorporation of this control in the experimental ring tunnel. This section of the test tunnel belongs to the surrounding II rock,

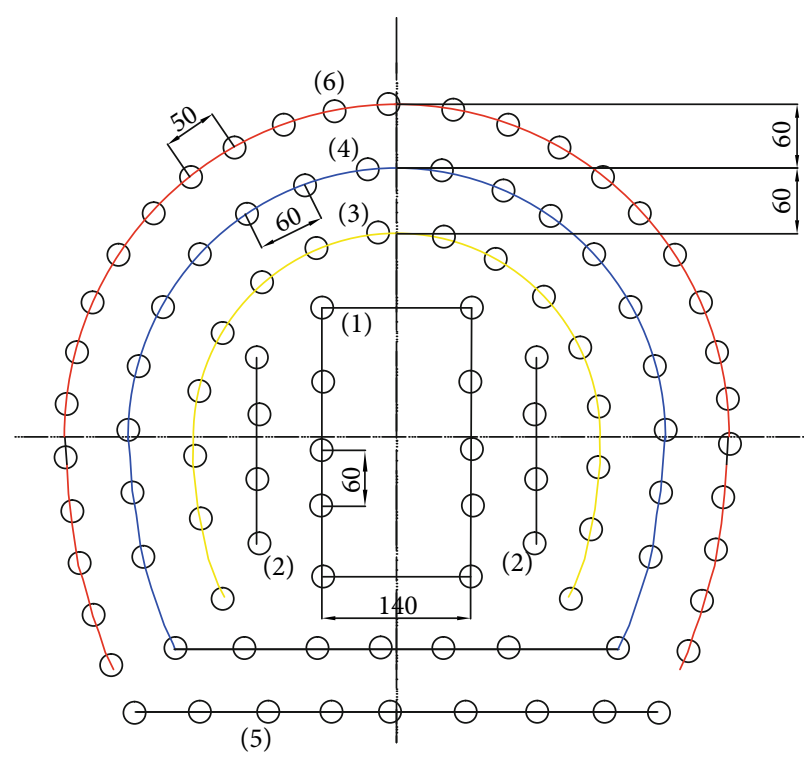

FIgURE 6: Layout diagram of the blasting holes.

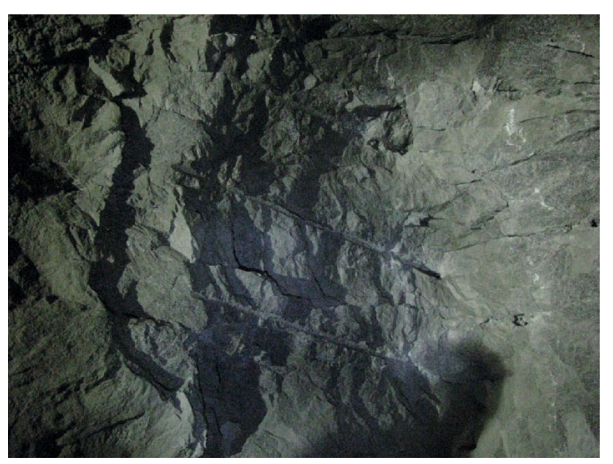

Figure 7: Actual tunnel contour after blasting.

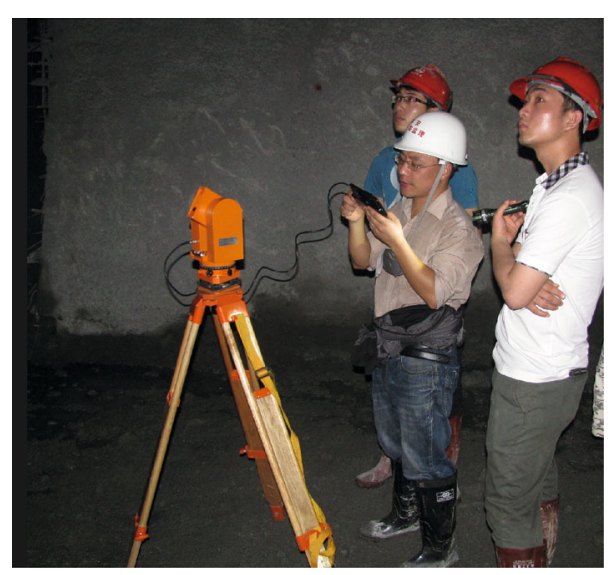

FIgURE 8: Tunnel profilometer.

and the designed tunnel radius is $3.1 \mathrm{~m}$. The test is conducted with full-face excavation and millisecond blasting. The smooth blasting parameters and the layout of the blast holes are summarized in Tables 2 and 3 and plotted in Figure 6. 


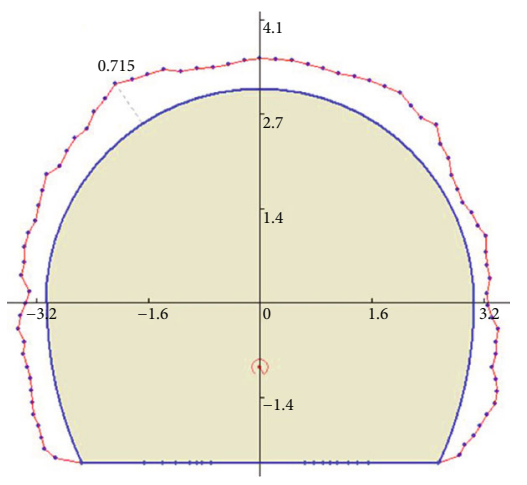

(a)

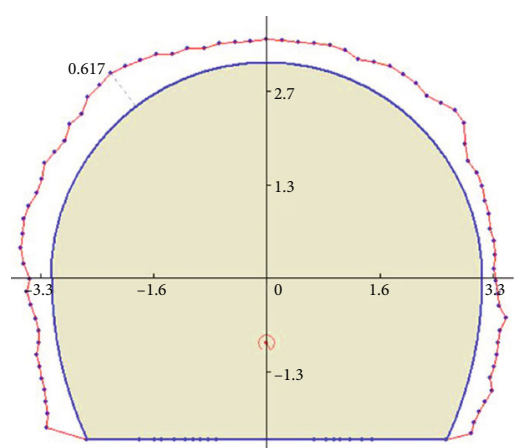

(c)

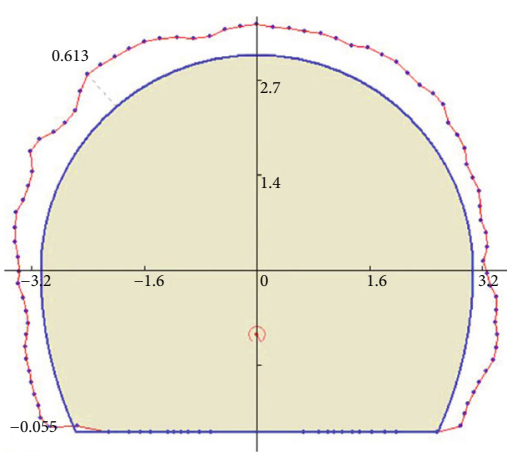

(b)

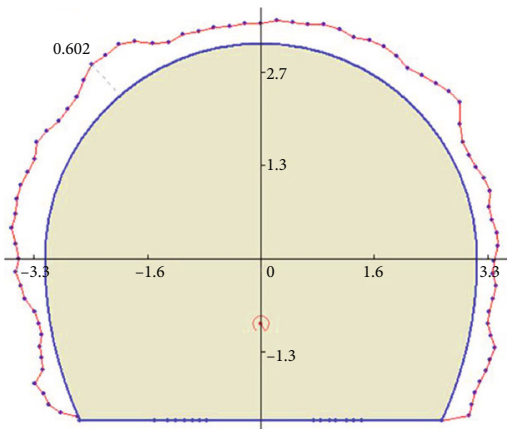

(d)

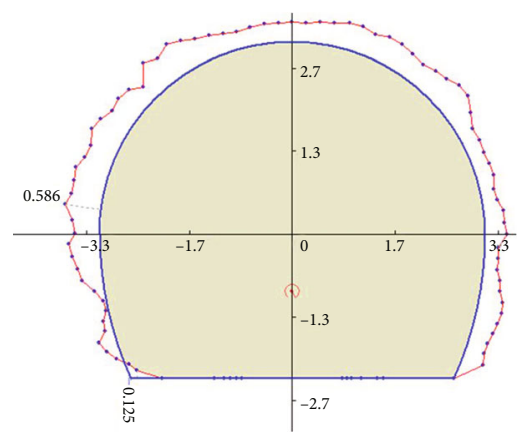

(e)

FIGURE 9: Effect of smooth blasting in the SSK0 + 712 excavation cycle for (a) surface no. 1, (b) surface no. 2, (c) surface no. 3, (d) surface no. 4, and (e) surface no. 5 .

Typical actual tunnel contour after smooth blasting is shown in Figure 7. Measurements of overbreaks are conducted at cross-sectional contours after each round of blasting, using a tunnel profilometer (see Figure 8). The tunnel profilometer is a ZTSD-3 laser measuring instrument for tunnel contours (made by Beijing Zhitengyongyi Co. Ltd.), with deformation accuracy of $1 \mathrm{~mm}$ and angle accuracy of $0.025^{\circ}$.

The surface no. 1 (SSK0 + 713.325), no. 2 (SSK0 + 713.625), no. 3 (SSK0 + 713.925), no. 4 (SSK0 + 714.225), and no. 5 $($ SSK0 +714.525$)$ are selected as the typical surfaces in the SSK $0+712$ excavation cycle. The implementation effects of the measurement surface are plotted in Figure 9. The comparison of the overbreak and underbreak control points is plotted in Figure 10. It can be seen that the tunnel at the left side of the maximum overbreak and the average linear overbreak is larger than that at the right side. The underbreak is observed at the left side of the tunnel. The index values of TSB are calculated as

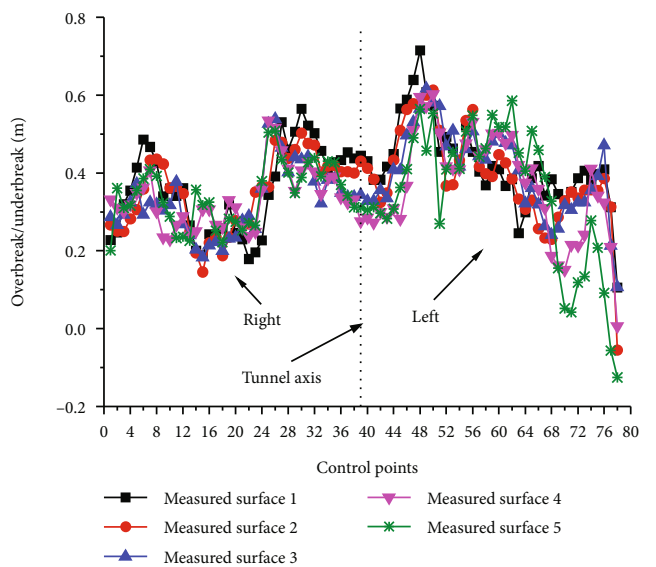

Figure 10: Comparison of the overbreak and underbreak control points. 
TABLE 4: Index values of tunnel smooth blasting before implementation.

\begin{tabular}{lcccc}
\hline $\begin{array}{l}\text { Number of sections for } \\
\text { measurement }\end{array}$ & $\begin{array}{c}\text { Overbreak area } \\
\left(\mathrm{m}^{2}\right)\end{array}$ & $\begin{array}{c}\text { Underbreak area } \\
\left(\mathrm{m}^{2}\right)\end{array}$ & $\begin{array}{c}\text { Maximum overbreak } \\
(\mathrm{m})\end{array}$ & $\begin{array}{c}\text { Average linear overbreak } \\
(\mathrm{m})\end{array}$ \\
\hline 1 & 6.01 & 0.00 & 0.71 & 0.32 \\
2 & 5.74 & 0.02 & 0.61 & 0.29 \\
3 & 5.61 & 0.00 & 0.62 & 0.30 \\
4 & 5.39 & 0.00 & 0.60 & 0.29 \\
5 & 5.33 & 0.05 & 0.59 & 0.30 \\
\hline
\end{tabular}

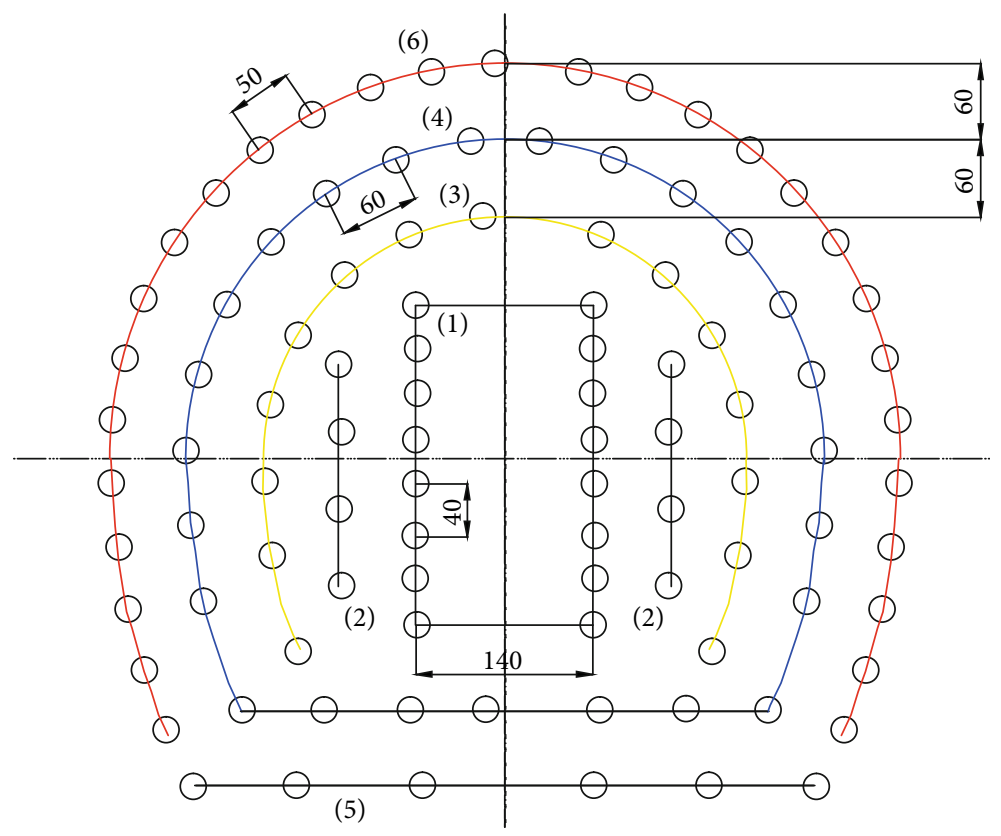

Figure 11: Layout of the adjusted smooth blasting holes.

shown in Table 4. The Android platform is also used to evaluate the quality of the SSK0 + 712 excavation cycle. The score of the smooth blasting quality is 5.82 at level four. Therefore, tunnel quality must be controlled.

4.3. Analysis of TSB Quality after Control. Based on the assessment results of TSB quality, the smooth blasting control was implemented into the SSK0 +715 excavation cycle of the tunnel to ensure TSB quality. The Android software platform is employed, and three neural network controls are proposed: (1) the BP neural network suggests that the perimeter hole spacing and hole charge should be decreased by $10 \%$ and $2 \%$, respectively; (2) the ANFIS neural network recommends that the perimeter hole spacing, hole charge, and minimum resistance line should be reduced by $20 \%$, $3 \%$, and $10 \%$, respectively; and (3) the Elman neural network suggests that the perimeter hole spacing and hole charge should be decreased by $20 \%$ and $3 \%$, respectively.

By combining the aforementioned suggestions with the implementation of comprehensive TSB quality, we can adjust the TSB scheme as follows: the tunnel at the left side of the cut hole depth measures $2.80 \mathrm{~m}$, the depth of the auxiliary hole and the perimeter hole is $2.50 \mathrm{~m}$, and hole charge is $0.60 \mathrm{~kg}$; meanwhile, the tunnel at the right side of the cut hole depth measures $2.50 \mathrm{~m}$, the depth of the auxiliary hole and the perimeter hole is $2.05 \mathrm{~m}$, and the hole charge is $0.50 \mathrm{~kg}$. The other perforation parameters and the layout are consistent with the original plan as shown in Figure 11. The typical measuring surface no. 1 (SSK0 + 716.113), no. $2(\mathrm{SSK} 0+716.313)$, no. 3 (SSK0 +716.513), and no. 4 $(\mathrm{SSK} 0+716.713)$ are also selected for analysis. The measured smooth blasting cycles for the four surfaces and the comparison of the overbreak and underbreak in the control points are shown in Figures 12 and 13, respectively. One photo of the tunnel surface after the SSK0-715 excavation cycle is shown in Figure 14. It can be seen that the maximum overbreak of the three other measured surfaces on the left side of the tunnel is larger than that of the surfaces on the right side, with the exception of measured surface 4 ; in this case, the largest overbreak in the tunnel is detected at the right side. The average linear overbreak at the right side of the tunnel is less than that at the left side. The parameter values of TSB after control implementation are listed in Table 5. The overall assessment grade of TSB 


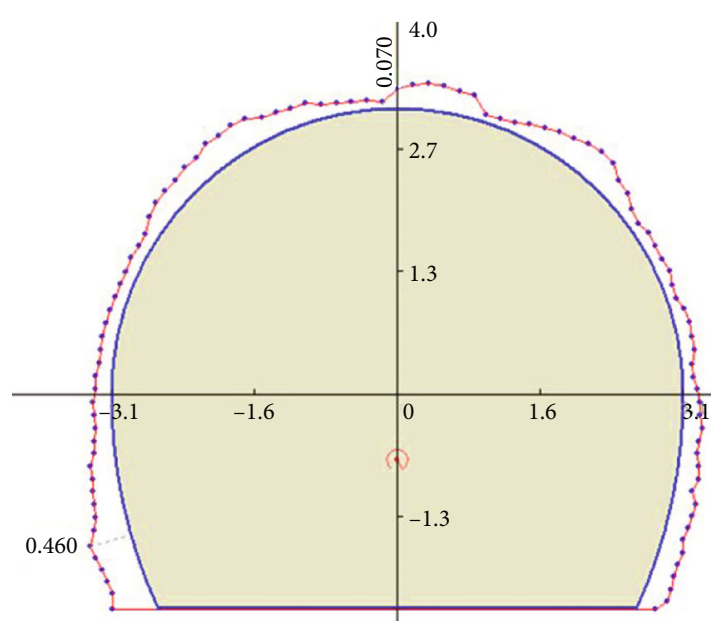

(a)

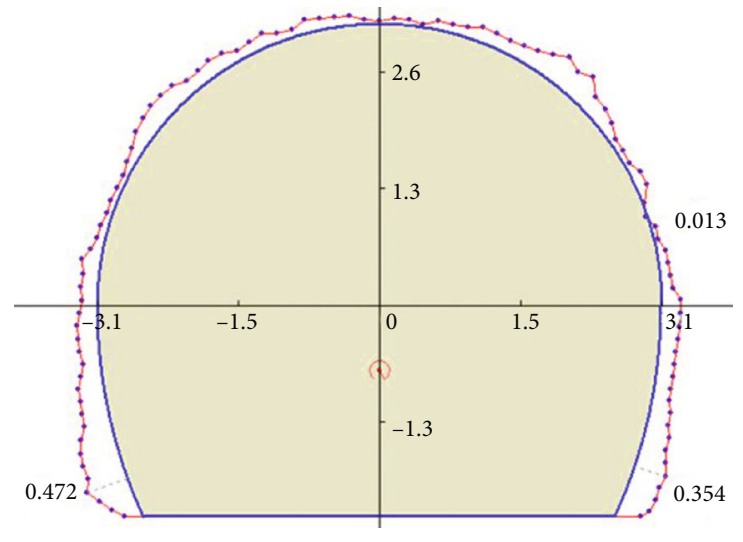

(c)

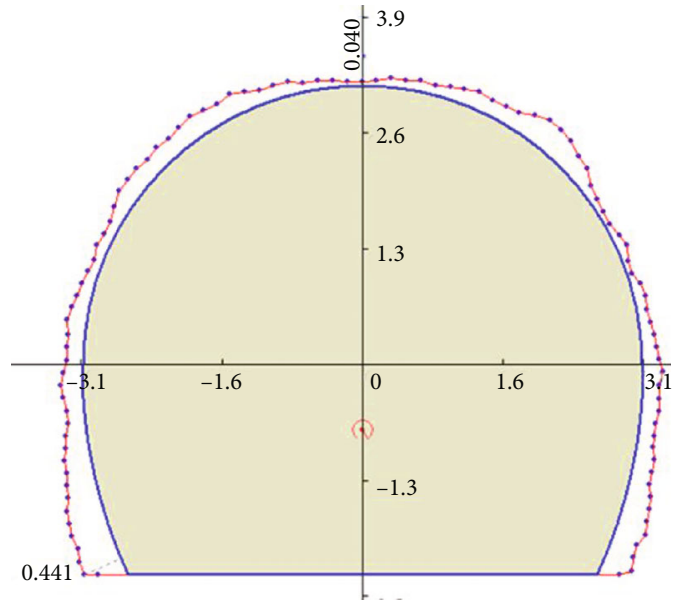

(b)

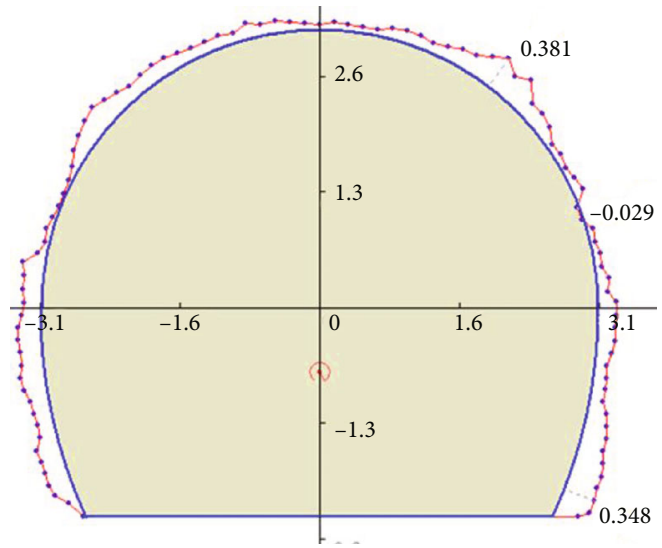

(d)

FIGURE 12: Effect of the SSK0 + 715 smooth blasting cycle for (a) surface no. 1, (b) surface no. 2, (c) surface no. 3, and (d) surface no. 4.

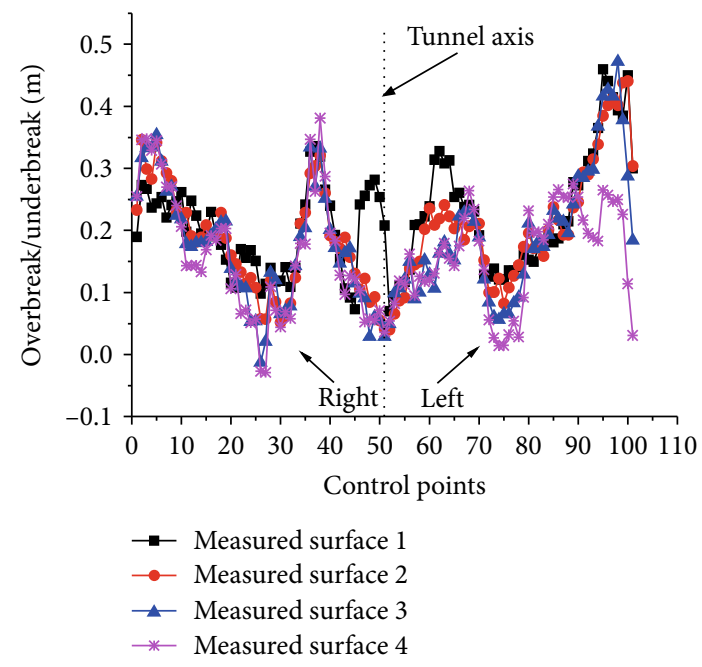

FIGURE 13: Comparison of the overbreak and underbreak control points.

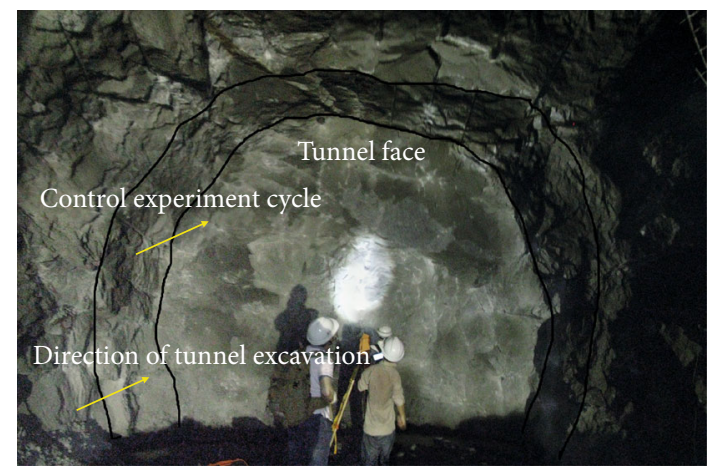

FIGURE 14: Overall effect of tunnel smooth blasting.

quality in SSK0-715 is reduced to level 3 which is acceptable for the overall evaluation. That is to say, with the use of the smooth blasting technique, the tunnel outline is regularized (see Figure 14). Moreover, the surface is smoothened and approaches the design contour. The borehole traces of the preservation rate are high, and the control effect of smooth blasting is strengthened. 
TABLE 5: Parameter values of tunnel smooth blasting after control implementation.

\begin{tabular}{lcccc}
\hline $\begin{array}{l}\text { Number of sections for } \\
\text { measurement }\end{array}$ & $\begin{array}{c}\text { Overbreak area } \\
\left(\mathrm{m}^{2}\right)\end{array}$ & $\begin{array}{c}\text { Underbreak area } \\
\left(\mathrm{m}^{2}\right)\end{array}$ & $\begin{array}{c}\text { Maximum overbreak } \\
(\mathrm{m})\end{array}$ & $\begin{array}{c}\text { Average linear overbreak } \\
(\mathrm{m})\end{array}$ \\
\hline 1 & 3.21 & 0.00 & 0.46 & 0.21 \\
2 & 2.85 & 0.00 & 0.44 & 0.20 \\
3 & 2.63 & 0.002 & 0.47 & 0.18 \\
4 & 2.34 & 0.003 & 0.38 & 0.16 \\
\hline
\end{tabular}

TABLE 6: Comprehensive comparison of controlled and uncontrolled systems for tunnel smooth blasting.

\begin{tabular}{lccc}
\hline & $\begin{array}{c}\text { Average value of the overbreak } \\
\text { area }\left(\mathrm{m}^{2}\right)\end{array}$ & $\begin{array}{c}\text { Mean value of average linear } \\
\text { overbreak }(\mathrm{m})\end{array}$ & $\begin{array}{c}\text { Maximum overbreak } \\
\text { average }(\mathrm{m})\end{array}$ \\
$\begin{array}{lccc}\text { Before control } \\
\text { implementation }\end{array}$ & 5.62 & 0.30 & 0.63 \\
$\begin{array}{l}\text { After control } \\
\text { implementation }\end{array}$ & 2.76 & 0.19 & 0.44 \\
Index decrease rate (\%) & 50.90 & 36.70 & 30.20 \\
\hline
\end{tabular}

To compare the effect and feasibility of the evaluation and control system for the quality of TSB, the overall effect of the implementation of TSB quality in controlled and uncontrolled systems is summarized in Table 6. Generally, the controlled system is more effective to control the TSB quality of the overbreak area, the average linear overbreak, and the maximum overbreak. In addition, the evaluation grade of the TSB quality improved from 4 to 3 after control implementation. This grade ensures tunnel blasting quality and the safety of tunnel construction. Furthermore, the speed and economic benefits of the tunnel excavation are enhanced.

4.4. Discussion. In this study, the intelligent evaluation and control platform has been developed based on the handheld mobile Android system for the tunnel smooth blasting which can be applied to tunnel design and construction management. This platform can overcome the drawbacks of traditional evaluation methods for TSB quality by incorporating the previous experience of policy makers and subjective understanding to determine grades of TSB quality, facilitate construction design, and select parameters for TSB. The platform can also adjust the parameters of this blasting, provide control suggestions, evaluate blasting quality, generate a reasonable TSB scheme, and improve tunnel blasting quality.

However, this platform is still insufficient for actual project application. The proposed control selection method can be improved further. This approach can be applied directly to the optimization design of a TSB scheme when this technique is consistent with the optimization control model that integrates three types of neural networks. However, the proposed control method must be appropriately adjusted by the designer based on actual blasting quality. Specifically, the suggestions of the ANFIS and the Elman neural networks are combined when the control suggestions are inconsistent with the comprehensive optimization control model that considers three types of neural networks. Therefore, control- ling this parameter selection situation can affect the intelligent control of TSB. The designed software platform lacks a hole layout plan. The recommendations of the control platform can be applied to smooth blasting construction in tunnels; however, these suggestions are not conducive to the construction and operation of on-site TSB given the lack of perforation scheme optimization after the adjustment plan is implemented. The software platform also lacks the comparison of engineering cost before and after blasting control, so the cost saving situation corresponding to blasting quality cannot be directly judged.

\section{Conclusions}

In this paper, a handheld mobile platform based on the Android system written in the Java language is proposed to evaluate and control the performance of the TSB. The design of the framework of the software includes system function, system module, and user interface. The proposed mobile platform was also applied to a real case history in metro line six in Guangzhou, China. The outcomes from the monitoring system were analyzed and evaluated to give a technical reference for the quality evaluation in TSB.

Using the proposed mobile platform, the end users can monitor and evaluate the TSB quality after each blasting. The software can also predict the results of the TSB through the various coded neural network prediction methods to guide the TSB in the field. The software platform exhibits the following features: (1) system functions of the software platform mainly include data input, data modification, data deletion, weight setting for evaluation, quality evaluation, and quality control; (2) the overall software platform system is composed of the main module as well as those for the data interface, update interface, weight setting, evaluation control, data storage service, and the database; (3) the software platform is designed with nine harmonious human-computer interfaces in line with service orientation principles; (4) as 
per the measured smooth blasting quality based on the Android platform, users can quickly and scientifically evaluate smooth blasting quality for each tunnel by employing the related evaluation system; (5) through the use of the control algorithm for established TSB quality, the software platform can rapidly guide the subsequent cycle of smooth blasting parameters by applying various neural network prediction methods for uncontrolled and controlled parameters and illustrating the measurement of the laser measuring instrument for tunnel sections; and (6) the software platform can be directly applied in practical engineering to guide construction.

\section{Data Availability}

The data are available and explained in this article; readers can access the data supporting the conclusions of this study.

\section{Conflicts of Interest}

The authors declare that there is no conflict of interests regarding the publication of this paper.

\section{Acknowledgments}

The financial support for this research project by the National Natural Science Foundation of China (Nos. 41602308 and 41572299), the Zhejiang Provincial Natural Science Foundation of China (No. LY20E080005), the graduate teaching reform research project of Zhejiang University of Science and Technology (Grant No. 2019yjsjg01), the Zhejiang Science and Technology Project (No. 2016C33033), and the Foundation of China Railway No.2 Engineering Group Co., Ltd. (No. 201218) is all gratefully acknowledged. The authors are grateful to Dr. Guo Wei from Tianjin University and Dr. Liu Xiaotian, Mr. Zhou Xiaobo, and Mr. Wang Guotao from Tongji University for providing useful information and discussion in this paper.

\section{References}

[1] R. Carter, "Software solutions for better blasting," Engineering and Mining Journal, vol. 213, no. 12, pp. 54-58, 2012.

[2] Z. Li, H. Liu, Z. Dun, L. Ren, and J. Fang, "Grouting effect on rock fracture using shear and seepage assessment," Construction and building materials, vol. 242, article 118131, 2020.

[3] Z. Li, H. Zhou, D. Hu, and C. Zhang, "Yield criterion for rocklike geomaterials based on strain energy and CMP model," International Journal of Geomechanics, vol. 20, no. 3, 2020.

[4] Z. Li, S. Liu, W. Ren, J. Fang, Q. Zhu, and Z. Dun, "Multiscale laboratory study and numerical analysis of water-weakening effect on shale," Advances in Materials Science and Engineering, vol. 2020, Article ID 5263431, 14 pages, 2020.

[5] X. Wang, C. Liu, S. Chen, L. Chen, K. Li, and N. Liu, "Impact of coal sector's de-capacity policy on coal price," Applied Energy, vol. 265, article 114802, 2020.

[6] Q. Meng, H. Wang, M. Cai, W. Xu, X. Zhuang, and T. Rabczuk, "Three-dimensional mesoscale computational modeling of soil-rock mixtures with concave particles," Engineering Geology, vol. 277, p. 105802, 2020.
[7] H. Abbaspour, C. Drebenstedt, M. Badroddin, and A. Maghaminik, "Optimized design of drilling and blasting operations in open pit mines under technical and economic uncertainties by system dynamic modelling," International Journal of Mining Science and Technology, vol. 28, no. 6, pp. 839-848, 2018.

[8] M. Cardu and J. Seccatore, "Quantifying the difficulty of tunnelling by drilling and blasting," Tunnelling and Underground Space Technology, vol. 60, pp. 178-182, 2016.

[9] M. Hasanipanah, D. Jahed Armaghani, M. Monjezi, and S. Shams, "Risk assessment and prediction of rock fragmentation produced by blasting operation: a rock engineering system,", Environmental Earth Sciences, vol. 75, no. 9, 2016.

[10] R. Yang, X. Ma, Q. Li, and Z. Zhang, “Application on intelligent system for optimization design of blasting in mine tunnel excavation of coal mine," Journal of China Coal Society, vol. 38, no. 7, pp. 1130-1135, 2013.

[11] K. Katsuyama, "Past and present of the computer simulation of blasting," Explosion, vol. 9, no. 1, pp. 2-9, 1999.

[12] A. Verma and T. Singh, "Intelligent systems for ground vibration measurement: a comparative study," Engineering with Computers, vol. 27, no. 3, pp. 225-233, 2011.

[13] D. M. La Rosa, “The development of an information management system for the improvement of drilling and blasting in mining operations," in Computer Applications in the Minerals Industry (APCOM) 2001, pp. 367-372, Beijing, China, 2001.

[14] C. Lee, Y. Jong, T. Kim, Y. Choi, and S. Jeon, "Development of an automated design program for tunnel blasting," Journal of the Japan Explosives Society, vol. 63, no. 6, pp. 309-315, 2002.

[15] V. Kecojevic and W. Wilkinson, "Computer-aided design and high-precision systems in drilling and blasting," Journal of Explosives Engineering, vol. 20, no. 5, pp. 12-14, 2003.

[16] X. Zhang, Y. Wu, E. Zhai, and P. Ye, "Coupling analysis of the heat-water dynamics and frozen depth in a seasonally frozen zone," Journal of Hydrology, vol. 593, article 125603, 2021.

[17] H. Y. Pan, D. W. Yin, N. Jiang, and Z. G. Xia, "Crack initiation behaviors of granite specimens containing crossing-doubleflaws with different lengths under uniaxial loading," Advances in Civil Engineering, vol. 2020, Article ID 8871335, 13 pages, 2020.

[18] D. K. Liu, Z. L. Gu, R. X. Liang et al., "Impacts of pore-throat system on fractal characterization of tight sandstones," Geofluids, vol. 2020, Article ID 4941501, 17 pages, 2020.

[19] L. L. Yang, W. Y. Xu, Q. X. Meng, and R. B. Wang, "Investigation on jointed rock strength based on fractal theory," Journal of Central South University, vol. 24, no. 7, pp. 1619-1626, 2017.

[20] Q. X. Meng, L. Yan, Y. L. Chen, and Q. Zhang, "Generation of numerical models of anisotropic columnar jointed rock mass using modified centroidal voronoi diagrams," Symmetry, vol. 10, no. 11, p. 618, 2018.

[21] Q. X. Meng and W. Wang, "A novel closed-form solution for circular openings in generalized Hoek-Brown media," Mathematical Problems in Engineering, vol. 2014, Article ID 870835, 7 pages, 2014.

[22] L. Yan, Q. X. Meng, W. Y. Xu et al., "A numerical method for analyzing the permeability of heterogeneous geomaterials based on digital image processing," Journal of Zhejiang University-SCIENCE A, vol. 18, no. 2, pp. 124-137, 2017.

[23] C. Shi, S. N. Wang, L. Liu, Q. X. Meng, and Q. Zhang, "Mesomechanical simulation of direct shear test on outwash 
deposits with granular discrete element method," Journal of Central South University, vol. 20, no. 4, pp. 1094-1102, 2013.

[24] W. R. Liu, J. K. Liu, and C. Zhu, "Multi-scale effect of acoustic emission characteristics of 3D rock damage," Arabian Journal of Geosciences, vol. 12, no. 22, 2019.

[25] X. Yang, J. Wang, D. Hou, C. Zhu, and M. He, "Effect of drywet cycling on the mechanical properties of rocks: a laboratory-scale experimental study," Processes, vol. 6, no. 10, p. 199, 2018. 